\title{
Circulating miR-127-3p as potential biomarker for differential diagnosis in
}

\section{Frontotemporal Dementia}

Paola Piscopo ${ }^{1}$, Margherita Grasso ${ }^{2}$, Maria Puopolo ${ }^{1}$, Emanuela D’Acunto ${ }^{1,3}$, Giuseppina Talarico $^{4}$, Alessio Crestini ${ }^{1}$, Marina Gasparini ${ }^{4}$, Rosa Campopiano ${ }^{5}$, Stefano Gambardella ${ }^{5}$, Anna Elisa Castellano ${ }^{5}$, Giuseppe Bruno ${ }^{4}$, Michela A. Denti ${ }^{2 * \S}$, Annamaria Confaloni $^{1 * \S}$.

${ }^{1}$ Department of Neuroscience, Istituto Superiore di Sanità, Rome, Italy

${ }^{2}$ Centre for Integrative Biology, University of Trento, Trento, Italy

${ }^{3}$ Department of Biology and Biotechnologies 'Charles Darwin', University of Rome "Sapienza", Rome, Italy

${ }^{4}$ Department of Human Neuroscience, University of Rome "Sapienza”, Rome, Italy

${ }^{5}$ Department of Neurology, IRCCS Neuromed Institute, Pozzilli, IS, Italy

Running title: miR-127-3p and Frontotemporal Dementia

$\S$ Corresponding Authors:

Annamaria Confaloni

Department of Neuroscience

Istituto Superiore di Sanità

Viale Regina Elena 299, 00161 Rome, Italy

Phone: +390649902930

Fax: +3949902040

E-mail: annamaria.confaloni@iss.it

Michela A. Denti

Laboratory of RNA Biology and Biotechnology

Centre for Integrative Biology - University of Trento

Via Sommarive 9, 38123 Trento, Italy

Phone:+390461283820

Fax: +390461283937

E-mail: michela.denti@unitn.it

* These authors contributed equally to the manuscript. 


\begin{abstract}
Given the heterogeneous nature of FTD, sensitive biomarkers are in great need for the accurate diagnosis of this neurodegenerative disorder. Circulating miRNAs have been reported as promising biomarkers for neurodegenerative disorders and processes affecting the central nervous system, especially in aging. The objective of the study was to evaluate if some circulating miRNAs linked with apoptosis (miR-29b-3p, miR-34a-5p, miR-16-5p, miR-17-5p, miR-107, miR-19b-3p, let-7b-5p, miR-26b-5p and 127-3p) were able to distinguish between FTD patients and healthy controls. For this study, we enrolled 127 subjects, including 54 patients with FTD, 20 patients with $\mathrm{AD}$ and 53 healthy controls. The qRT-PCR analysis showed a down-regulation of miR-127-3p in FTD compared to controls, while the levels of other miRNAs remained unchanged. Then, miR-127-3p expression was also analysed in AD patients, finding a different expression between two patient groups. A receiver operating characteristic (ROC) curve was then created for miR-127-3p to discriminate FTD versus AD (AUC: 0.8986), and versus healthy controls (AUC: 0.8057). In conclusion, miR-127-3p could help to diagnose FTD and to distinguish it from AD.
\end{abstract}

Keywords: Frontotemporal dementia, miR-127-3p, differential diagnosis, biomarker, miRNA.

\title{
Introduction
}

Frontotemporal lobar degeneration (FTLD) is a neurodegenerative syndrome characterized by atrophy in the frontal and temporal lobes of the brain $[1,2]$. The disorder is the third most common dementia subtype with a prevalence ranging from $3 \%$ to $26 \%$ [3]. Clinically, patients show with either changes in behaviour and personality (behavioural variant FTD, bvFTD), or language impairment (primary progressive aphasia, PPA). PPA can be further divided into two main subtypes, semantic variant (svPPA) and non-fluent variant (nfvPPA) [4]. Moreover, different mutations have been found in genes such as those encoding Microtubule Associated 
Protein Tau (MAPT), Progranulin (GRN), Chromosome 9 open reading frame 72 (C9ORF72), TAR DNA-binding protein 43 (TDP-43), Fused in Sarcoma binding protein (FUS), Valosin-Containing Protein (VCP), Charged Multivesicular Body Protein 2B (CHMP2B) [5] and, recently, TANK-binding kinase 1 [6].

The diagnosis of the FTD spectrum of diseases is based on clinical symptoms. This hampers the differentiation of the diseases among each other and with other disorders that show a similar clinical appearance resulting in a high rate of misdiagnoses, so that a total of $10-30 \%$ of patients presenting with an FTD clinical syndrome are found to have Alzheimer's disease on autopsy [7].

Accurate diagnosis is important for early and correct treatment of the diseases and for drug development. Great efforts have been made in the past to identify biomarkers especially in the CSF to improve differential diagnosis of FTD [8], but only a few potential biomarker candidates have been described in recent years. In this scenario, new biomarkers for FTD are needed to improve differential diagnosis within the disease spectrum and for related neurodegenerative diseases such as AD.

Notably, circulating miRNAs have been reported as promising biomarkers for neurodegenerative disorders and processes affecting the central nervous system, especially in aging $[9,10]$.

Different studies showed that miRNAs are playing an important role in FTD pathology $[11,12]$. For example, several reports have evaluated miRNAs regulation of the progranulin gene, suggesting that it is under their control, as described for miR-29b, miR-107 and miR659 [13-15].

Apoptosis appears to play a key role in the progression of several neurologic disorders as demonstrated by studies on animal models and cell lines [16,17]. Brains of patients with neurodegenerative diseases are usually associated with significant cell loss accompanied by 
typical morphological features of apoptosis such as chromatin condensation, DNA fragmentation, and activation of cysteine-proteases [18]. To date, we know from literature that miR-29b-3p, miR-34a-3p,miR-16-5p, miR-17-5p, mir-107,miR-19b-3p, let-7b-5p and miR-127-3p mediate apoptosis induced by hypoxic/ischemic or spinal cord injury. Moreover, miR-26b causes activation of cyclin-dependent kinase 5 and increase tau phosphorylation, followed by apoptosis and neurodegeneration. Therefore, we wondered whether the levels of these miRNAs were abnormal in the plasma of patients with frontotemporal dementia [1941]. To search for novel plasma miRNA signatures that can distinguish patients from healthy individuals, we selected nine miRNAs (miR-29b-3p, miR-34a-5p, miR-16-5p, miR-17-5p, miR-107, miR-19b-3p, let-7b-5p, miR-26b-5p and miR-127-3p), which have been reported to be closely correlated with apoptosis and/or dementia.

\section{Materials and Methods}

\section{Patient recruitment and clinical evaluation}

Subjects were recruited consecutively at the Memory Clinic of University "Sapienza" (Rome, Italy), and at the Alzheimer's Unit of IRCCS Neuromed (Pozzilli, Italy).

The study was approved by the Institutional Review Board of all centers and a written informed consent approved by the ethics committees was obtained from all participants involved in this study. The clinical diagnosis of probable FTD was defined according to current consensus criteria $[42,43]$. The clinical diagnosis of probable AD was defined according to the DSM-IV and Alzheimer's disease and Related Disorders Association (NINCDS-ADRDA) criteria [44] in a consensus diagnostic conference by a panel of neurologists and neuropsychologists. The healthy control groups $(\mathrm{Ctrl})$ were enrolled among healthy volunteers: family members or caregivers unrelated to the patients, all undergoing a 
clinical interview with a neurologist with a completely normal cognitive and functional assessment. Moreover, all patients underwent standard evaluations that included I) a detailed clinical history recorded from the patients and/or caregivers; II) an extensive physical exam; III) neurological examination; IV) an extensive neuropsychological testing including the Mini Mental State Examination (MMSE); V) laboratory tests to exclude secondary causes of dementia; VI) brain imaging (magnetic resonance imaging or computerized tomography) and VII) in the most cases, 99mTc-HMPAO SPECT or FDG PET scan. Healthy subjects underwent clinical and neurological assessment including the administration of MMSE. All FTD patients were screened for possible mutations in MAPT, GRN and C9ORF72 genes.

\section{RNA isolation from plasma.}

Whole blood was recovered in tubes treated with EDTA and centrifuged for $15 \mathrm{~min}$ at 2500 rpm at $4^{\circ} \mathrm{C}$. Plasma layer was carefully collected without shaking the buffy coat. Total RNA was extracted from $250 \mu \mathrm{L}$ of plasma using a miRNeasy mini kit (Qiagen), following the manufacturer's recommendations. $1 \mu \mathrm{g}$ of MS2 bacteriophage RNA (Roche Diagnostics) was added to each sample to improve endogenous RNA recovery. Qubit RNA HS Assay Kit (Thermo Fisher Scientific) was used with the Qubit Fluorometer, to provide an accurate method for the quantification of low-abundance RNA samples. Evaluation of possible hemolysis contamination was carried out by comparing the level of a miRNA highly expressed in red blood cells (hsa-miR-451a), with a miRNA unaffected by hemolysis (hsamiR-23a-3p) [45]. $\Delta \mathrm{Ct}$ (miR-23a-3p - miR-451a) gives a measure of hemolysis degree: $\Delta \mathrm{Ct}$ values of more than five indicate a possible erythrocyte miRNA contamination, and values of 7-8 or more a high risk of hemolysis. 
miRNA Reverse Transcription and quantitative Real Time PCR (qRT-PCR).

80 ng of extracted RNA were retro-transcribed using Universal cDNA Synthesis kit (Exiqon) according to the manufacturer's protocol. cDNA template was then diluted 50X in nuclease free water and mixed 1:1 with 2X PCR Master Mix (Exiqon). For miRNA quantitative PCR assays, samples were analysed in triplicates using miRCURY $\mathrm{LNA}^{\mathrm{TM}}$ PCR primers set (Exiqon): hsa-miR-127-3p, hsa-miR-29b-3p, hsa-miR-191-5p, hsa-let-7d-5p, hsa-miR-107, hsa-miR-132 and endogenous control hsa-miR-93-5p. qRT-PCR reactions were performed using ExiLENT SYBR ${ }^{\circledR}$ Green master mix (Exiqon) in a CFX384 Real-Time PCR Detection System (Bio-Rad Laboratories). $10 \mu \mathrm{l}$ PCR reaction contained $2 \mu 1$ of the 1:80 diluted cDNA template, $5 \mu 1$ of $\mathrm{SYBR}^{\circledR}$ Green master mix and $1 \mu 1$ of PCR primer mix. The reaction protocol was as follows: $95^{\circ} \mathrm{C}$ for 10 minutes, followed by 40 amplification cycles of $95^{\circ} \mathrm{C}$ for 10 seconds and $60^{\circ} \mathrm{C}$ for 1 minute. Raw $\mathrm{Ct}$ values were normalized using the $\Delta \mathrm{Ct}$ method with respect to the endogenous control. In order to select the endogenous control, we tested five miRNAs as reference genes (hsa-miR-93-5p, hsa-miR-103, hsa-miR-191, hsa-miR-423$3 p$, and hsa-miR-425-5p) checking their expression levels and stability in our samples by using Normfinder and Genorm software $[46,47]$.

\section{Statistical analysis}

Continuous data are summarized by mean and standard error, or median and interquartile range. Categorical variables are described by frequency and percentage distributions. Comparisons between experimental groups were assessed by the t-test or Mann-Whitney test for continuous variables, and by Fisher's exact probability test and Pearson's chi-square test for categorical variables. Spearman's rank correlation coefficient was used to investigate association between continuous variables. 
The effectiveness of $\Delta \mathrm{Ct}$ in discriminating between groups was assessed by the Receiver Operating Characteristic (ROC) curve analyses. Non-parametric ROC curves were obtained for FTD vs Ctrl and FTD vs AD. The area under the ROC curve (AUC) and its 95\% confidence interval $(95 \% \mathrm{CI})$ were calculated as a measure of diagnostic accuracy. Cut-points for $\Delta \mathrm{Ct}$ with fixed sensitivity and specificity were obtained from analysis of the ROC curve. The level of significance was 0.05 and Bonferroni's correction was adopted to control for type I error in multiple comparisons. All statistical analyses were carried out by the software STATA 13 (StataCorpLP).

\section{Results}

127 subjects were enrolled in our study, including 54 probable FTD patients (31 bvFTD and 23 PPA), 20 AD patients and $53 \mathrm{Ctrl}$. Patient and Ctrl characteristics are summarized in Table 1. All patients had a MMSE ranging from 10 to 24 .

All patients were sporadic and no mutations were found in the most genes involved in FTD, $M A P T, G R N$ and C9ORF72. Before the qRT-PCR, we verified possible cellular and haemolysis contamination and to minimize the carry-over of inhibitors into the RNA samples monitoring sample quality, in order to successfully analyse miRNAs expression. Then, we selected and tested five miRNAs as reference genes (hsa-miR-93-5p, hsa-miR-103, hsa-miR191, hsa-miR-423-3p, and hsa-miR-425-5p). We checked their expression levels and stability in our samples by using Normfinder and Genorm software, showing that miR-93-5p is the most highly expressed and stable among the five selected miRNAs (Supplementary Figure 1). miR-29b, miR-34a, miR-16-5p, miR-17-5p, miR-107, miR-19, let-7b, miR-26b and miR-127$3 p$ were screened by qRT-PCR, as possible candidate miRNAs able to discriminate FTD from cognitively healthy controls. The analysis showed the down-regulation of miR-127-3p in FTD respect to $\mathrm{Ctrl}(0.017 \pm 0.003$ vs $0.058 \pm 0.007 \mathrm{p}<0.0001)$ (Fig. 1 and Table 2$)$. The other 
analyzed miRNAs did not show significant difference in FTD with respect to Ctrl (Supplementary Figure 2).

miR-127-3p expression was also analysed in patients with $\mathrm{AD}$, finding a different expression between them (FTD $0.017 \pm 0.003$ vs AD $0.078 \pm 0.014 \mathrm{p}<0.0001$ ). Moreover, an up-regulation of miR-127-3p was observed in AD subjects with respect to Ctrl, close to significance (AD $0.078 \pm 0.014$ vs Ctrl 0.058 $\pm 0.007 \mathrm{p}=0.18$ ) (Fig. 1 and Table 2).

When all subjects were stratified on subgroups by gender, we found that significant differences of miR-127-3p levels between FTD and Ctrl, and between FTD and AD were observed both in males and in females (Fig. 2).

Diagnostic accuracy of miR-127-3p expression levels was measured by AUC (95\% CI) of ROC curves. AUC to discriminate FTD was 0.8057 (0.7242-0.8872) versus Ctrl (Fig. 3A) and 0.8986 (0.8275-0.9697) versus AD (Fig.3B). The optimal cut-off values for detecting FTD vs Ctrl were selected. When the relative miR-127-3p value is under $\Delta \mathrm{Ct} 5.5$, the sensitivity was $81.48 \%$ and the specificity was $69.81 \%$. Moreover, the optimal cut-off values for detecting FTD vs AD were selected, as well. When the relative miR-127-3p value is under $\Delta \mathrm{Ct} 5.5$, the sensitivity was $81.48 \%$ and the specificity was $80.00 \%$ (Table 3 ). As the box-plot in Fig. 1 shows some outliers, we tried to analyze diagnostic accuracy of miR-127-3p excluding them. We observed an AUC of 0.8382 (0.7602-0.9163) for FTD vs Ctrl and 0.9361 (0.8788-0.9934) for FTD vs AD (Supplementary Figure 3).

When distinguished by gender, AUCs of miR-127-3p value to discriminate FTD versus Ctrl was 0.7684 in male (Fig. 4A) and 0.8264 in female (Fig. 4B) and to discriminate FTD versus AD was 0.9263 in males (Fig. 4C) and 0.8714 in females (Fig. 4D).

\section{Correlation of miR-127-3p level with clinical scores}

The lag from disease onset to evaluation [median (IQR): 4.5 (4) and 4 (4), for FTD and AD respectively] did not differ among FTD and AD patients (Mann Whitney test, $\mathrm{p}=0.9363$ ). 
Moreover, there was no correlation between age at onset and lag from disease onset to evaluation (spearman's rank correlation coefficient ( $p$-value): $-0.2243(p=0.1030)$ and -0.16 $(p=0.4939)$ in FTD and AD respectively. Furthermore, miR-127-3p levels were not associated to lag from disease onset to evaluation both in FTD and in AD patients [Spearman's rank correlation coefficient ( $\mathrm{p}$-value): $-0.0734(\mathrm{p}=0.5981)$ and $-0.3810(\mathrm{p}=0.0974)$, in FTD and AD respectively]. MMSE at evaluation was available for 51 of 54 FTD patients and for all AD patients. It did not differ among FTD and AD patients [median (IQR): 22 (13) and 18.5 (10.5) for FTD and AD respectively; Mann Whitney, $p=0.0920)$ ]. miR-127-3p levels were not associated with MMSE both in FTD and in AD patients (Spearman's rank correlation coefficient ( $p$-value): $-0.0823(p=0.5698)$ and $-0.1198(p=0.6148)$.

\section{Discussion}

Difficulties in accurate diagnosis of FTD require sensitive biomarkers support given the heterogeneous nature of the disorder. Great efforts to identify these biomarkers have been made over the past two decades, with a predominant focus on fluid biomaterial and neuroimaging features. In FTD, diagnostic biomarkers should discriminate among individuals with FTD, healthy subjects and individuals with other neurodegenerative diseases, and/or should differentiate among clinical, genetic or pathological subtypes. Staging biomarkers should enable us to assess disease severity and to discriminate between presymptomatic, prodromal, and early or late symptomatic stages of the disease.

In this work, we propose a new biomarker, miR-127-3p, useful to improve the diagnosis of FTD. This is the first study demonstrating the dysregulation of miR-127-3p in plasma of patients with FTD. Although miR-127-3p is mainly known for its role in tumor diseases $[48,49]$, experimental data show that it affects the induction of neuronal apoptosis by regulating the expression of mitoNEET, an iron-sulfur cluster transfer protein that binds to the 
mitochondrial outer membrane [38]. In the central nervous system, miR-127-3p has been also described as a neuron-enriched miRNA playing a central role in neuronal differentiation $[50,51]$.

Other authors have shown that the down-regulation of miR-127 in rat liver cells promotes cell proliferation, while its up-regulation inhibits proliferation [52].

These observations suggest an important role for this miRNA in cell proliferation, differentiation, and development. Chen and colleagues observed that miR-127 induces senescence in human fibroblasts and inhibits the proliferation of breast cancer cells by targeting the oncogene BCL6; they suggest miR-127 as a novel senescence-associated (SA)miRNA regulating cellular senescence [53].

Recently, miR-127-3p has also been considered a possible biomarker of different neurodegenerative diseases. Burgos and colleagues, profiling miRNAs content in CSF and serum by Next Generation Sequencing (NGS), found miR-127-3p up-regulated in AD serum and down-regulated in $\mathrm{AD}$ CSF when compared to neurologically normal age-matched controls. Moreover, miR-127-3p was also found down-regulated in CSF of PD patients compared with control subjects [54]. In our study on plasma, we observed a similar trend to Burgos' serum data, but the statistical analysis resulted not significant $(p=0.18)$. Other authors have detected miR-127 involvement in other Neurodegenerative Diseases (NDs), such as Multiple Sclerosis (MS). Small RNA NGS was performed to profile exosome-associated miRNAs in serum samples from MS patients and healthy controls. They identified differentially expressed exosomal miRNAs in both relapsing-remitting MS (RRMS) and progressive MS patient sera in relation to controls. miR-127-3p was found up-regulated in progressive MS patients with respect to controls [55].

In our study, we show that expression levels of miR-127-3p were lower in plasma from FTD patients compared to subjects with AD. Several works attempted to identify miRNAs, as 
useful candidates in the clinical differential diagnosis of dementia particularly for AD. A recent study investigated miRNAs expression patterns in patients diagnosed with AD and patients diagnosed with either vascular dementia, frontotemporal dementia or dementia with Lewy bodies. They found that miR-29c-3p and miR-15a-5p had the highest classification accuracies separately, and by combing them in a simple ratio model (RELmiR-29c3p/RELmiR-15a-5p), they found that AD patients could be distinguished from patients with other types of dementia (cut-off value 0.92 ) with a sensitivity of $90 \%$ and a specificity of $100 \%$ [56]. In another work investigating the assessment of circulating brain-enriched miRNAs as potential biomarkers for AD, FTD, PD, and amyotrophic lateral sclerosis (ALS), the authors revealed miRNA classifiers capable of differentiating NDs from each other with accuracy ranging from 0.77 (AUC, 0.87) for AD vs FTD to 0.93 (AUC, 0.98) for AD vs ALS [57]. Moreover, Vallelunga and colleagues, identified three up-regulated miRNAs in serum of MSA patients (miR-24, miR-34b, miR-148b) in comparison to PD patients [58].

By analysing all subjects on subgroups characterized by gender, we found that miR-127-3p is differential expressed in FTD in both males and females. We chose to extend the analysis by gender considering that miR-127-3p is regulatedby estrogen related receptor gamma (ERRc) [59]. Actually, recent studies suggest that the regulation of miRNA expression levels might be influenced by hormonal and genetic background [60]. Ziats and colleagues evaluated the gender-dependent miRNA expression in the prefrontal cortex of human brain. They discovered 40 miRNAs with significant expression differences between the prefrontal cortex of males and females. Strikingly, 93\% were more highly expressed in females [61]. Several studies showed sex differences in miRNAs expression in patients with neurological diseases. Sheinerman and colleagues revealed sex dependence of certain brain-enriched miRNAs, which distinguished NDs from HC in sex-specific subsets with a significantly higher accuracy than in the total (female and male) population [57]. In another study, Denk and colleagues 
described gender specific differences concerning miR-106a, miR-17, miR-320, miR-19a, miR-221, miR-532, miR-95 in CSF of AD patients [62]. Moreover, miR-30b, regulated by estrogens, was observed to be significantly down-regulated in female schizophrenic brains with respect to males [63]. Then, not considering possible differences between males and females in miRNA and, in general, in biomarker analysis could introduce a gender-bias in the study[64].

Few literatures exist on role of miR-127 in brain, so that speculating about a disease-specific pathogenic mechanism that could explain differences between AD and FTD is not possible. Additional studies exploring a potential biological function of this miRNA circulating in body fluids are required.

A limit of the study is the lack of a MCI population to investigate miR-127 as biomarker for early diagnosis in a longitudinal study. The cohort Studies of Memory in an International Consortium (COSMIC) estimated MCI prevalence to be $5.9 \%$ in people 60 years and older [65]. The annual rate in which MCI progresses to dementia was $9.6 \%$ [66], even if an overall $18 \%$ reversion rate from MCI to NC was calculated, as well [67]. In those MCI cases destined to develop a dementia, biomarkers are emerging to help identify etiology and predict progression. In fact, subjects with MCI could benefit from early diagnosis and consequently potential treatment options, thus delaying their evolution and improving their quality of life and that of their relatives [68].

In conclusion, we show that expression levels of miR-127-3p were decreased in plasma from FTD patients compared to healthy subjects and patients with $A D$, suggesting that miR-127-3p could help to diagnose FTD and to distinguish it from AD. 
Acknowledgments: This work was supported by a "Futuro in Ricerca" - Italian Ministry of

Education, University and Research Grant (Grant number RBFR-0895DC) to MAD and by

“ALANonlus" NPO (non-profit organization) to AC.

\section{Conflict of interest}

The authors have no conflict of interest to report.

\section{References}

[1] Cardarelli R, Kertesz A, Knebl JA (2010) Frontotemporal dementia: a review for primary care physicians. Am. Fam. Physician82, 1372-7.

[2] Seltman RE, Matthews BR (2012) Frontotemporal Lobar Degeneration. CNS Drugs 26, 841-870.

[3] Vieira RT, Caixeta L, Machado S, Silva AC, Nardi AE, Arias-Carrión O, Carta MG (2013) Epidemiology of early-onset dementia: a review of the literature. Clin. Pract. Epidemiol. Ment. Heal.9, 88-95.

[4] Bang J, Spina S, Miller BL (2015) Frontotemporal dementia. Lancet386, 1672-1682.

[5] Fontana F, Siva K, Denti MA (2015) A network of RNA and protein interactions in Fronto Temporal Dementia. Front. Mol. Neurosci.8, 9.

[6] Pottier C, Bieniek KF, Finch N, van de Vorst M, Baker M, Perkersen R, Brown P, Ravenscroft T, van Blitterswijk M, Nicholson AM, DeTure M, Knopman DS, Josephs KA, Parisi JE, Petersen RC, Boylan KB, Boeve BF, Graff-Radford NR, Veltman JA, Gilissen C, Murray ME, Dickson DW, Rademakers R (2015) Whole-genome sequencing reveals important role for TBK1 and OPTN mutations in frontotemporal lobar degeneration without motor neuron disease. Acta Neuropathol.130, 77-92.

[7] Rabinovici GD, Miller BL (2010) Frontotemporal Lobar Degeneration. CNS Drugs24, 375-398.

[8] Oeckl P, Steinacker P, Feneberg E, Otto M (2015) Cerebrospinal fluid proteomics and protein biomarkers in frontotemporal lobar degeneration: Current status and future perspectives. Biochim. Biophys. Acta - Proteins Proteomics1854, 757-768.

[9] Olivieri F, Spazzafumo L, Santini G, Lazzarini R, Albertini MC, Rippo MR, Galeazzi R, Abbatecola AM, Marcheselli F, Monti D, Ostan R, Cevenini E, Antonicelli R, Franceschi C, Procopio AD (2012) Age-related differences in the expression of circulating microRNAs: miR-21 as a new circulating marker of inflammaging. Mech. Ageing Dev.133, 675-685.

[10] ElSharawy A, Keller A, Flachsbart F, Wendschlag A, Jacobs G, Kefer N, Brefort T, Leidinger P, Backes C, Meese E, Schreiber S, Rosenstiel P, Franke A, Nebel A (2012) Genome-wide miRNA signatures of human longevity. Aging Cell11, 607-616.

[11] Grasso M, Piscopo P, Confaloni A, Denti MA (2014) Circulating miRNAs as biomarkers for neurodegenerative disorders. Molecules 19, 6891-910.

[12] Piscopo P, Albani D, Castellano AE, Forloni G, Confaloni A (2016) Frontotemporal Lobar Degeneration and MicroRNAs. Front. Aging Neurosci.8, 17.

[13] Hébert SS, Horré K, Nicolaï L, Papadopoulou AS, Mandemakers W, Silahtaroglu AN, 
Kauppinen S, Delacourte A, De Strooper B (2008) Loss of microRNA cluster miR29a/b-1 in sporadic Alzheimer's disease correlates with increased BACE1/betasecretase expression. Proc. Natl. Acad. Sci. U. S. A.105, 6415-20.

[14] Noren Hooten N, Abdelmohsen K, Gorospe M, Ejiogu N, Zonderman AB, Evans MK (2010) microRNA expression patterns reveal differential expression of target genes with age. PLoS One5, e10724.

[15] Piscopo P, Rivabene R, Adduci A, Mallozzi C, Malvezzi-Campeggi L, Crestini A, Confaloni A (2010) Hypoxia induces up-regulation of progranulin in neuroblastoma cell lines. Neurochem. Int.57, 893-8.

[16] Honig LS, Rosenberg RN (2000) Apoptosis and neurologic disease. Am. J. Med.108, 317-30.

[17] Favaloro B, Allocati N, Graziano V, Di Ilio C, De Laurenzi V (2012) Role of apoptosis in disease. Aging (Albany. NY).4, 330-49.

[18] Ghavami S, Shojaei S, Yeganeh B, Ande SR, Jangamreddy JR, Mehrpour M, Christoffersson J, Chaabane W, Moghadam AR, Kashani HH, Hashemi M, Owji AA, Łos MJ (2014) Autophagy and apoptosis dysfunction in neurodegenerative disorders. Prog. Neurobiol.112, 24-49.

[19] Cao L, Zhang Y, Zhang S, Jiang T-P, Chen L, Liu J, Zhou S (2018) MicroRNA-29b alleviates oxygen and glucose deprivation/reperfusion-induced injury via inhibition of the p53-dependent apoptosis pathway in N2a neuroblastoma cells. Exp. Ther. Med.15, $67-74$.

[20] Qi Y, Zhang M, Li H, Frank JA, Dai L, Liu H, Chen G (2014) MicroRNA-29b regulates ethanol-induced neuronal apoptosis in the developing cerebellum through SP1/RAX/PKR cascade. J. Biol. Chem. 289, 10201-10.

[21] Wang G, Yao J, Li Z, Zu G, Feng D, Shan W, Li Y, Hu Y, Zhao Y, Tian X (2016) miR-34a-5p Inhibition Alleviates Intestinal Ischemia/Reperfusion-Induced Reactive Oxygen Species Accumulation and Apoptosis via Activation of SIRT1 Signaling. Antioxid. Redox Signal.24, 961-973.

[22] Wang X, Xie Y, Wang J (2017) Overexpression of MicroRNA-34a-5p Inhibits Proliferation and Promotes Apoptosis of Human Cervical Cancer Cells by Downregulation of Bcl-2. Oncol. Res.

[23] Chen Q, Li L, Tu Y, Zheng L, Liu W, Zuo X, He Y, Zhang S, Zhu W, Cao J, Cui F, Hou J (2014) MiR-34a regulates apoptosis in liver cells by targeting the KLF4 gene. Cell. Mol. Biol. Lett.19, 52-64.

[24] Cai B, Ma M, Chen B, Li Z, Abdalla BA, Nie Q, Zhang X (2018) MiR-16-5p targets SESN1 to regulate the $\mathrm{p} 53$ signaling pathway, affecting myoblast proliferation and apoptosis, and is involved in myoblast differentiation. Cell Death Dis.9, 367.

[25] Qu Y, Liu H, Lv X, Liu Y, Wang X, Zhang M, Zhang X, Li Y, Lou Q, Li S, Li H (2017) MicroRNA-16-5p overexpression suppresses proliferation and invasion as well as triggers apoptosis by targeting VEGFA expression in breast carcinoma.

Oncotarget8, 72400-72410.

[26] Wang Q, Zhan Y, Ren N, Wang Z, Zhang Q, Wu S, Li H (2018) Paraquat and MPTP alter microRNA expression profiles, and downregulated expression of miR-17-5p contributes to PQ-induced dopaminergic neurodegeneration. J. Appl. Toxicol.38, 665677.

[27] Hao M-X, Wang X, Jiao K-L (2017) MicroRNA-17-5p mediates hypoxia-induced autophagy and inhibits apoptosis by targeting signal transducer and activator of transcription 3 in vascular smooth muscle cells. Exp. Ther. Med.13, 935-941.

[28] Jiao Y, Kong L, Yao Y, Li S, Tao Z, Yan Y, Yang J (2016) Osthole decreases beta amyloid levels through up-regulation of miR-107 in Alzheimer's disease. 
Neuropharmacology108, 332-344.

[29] Yang Z-B, Zhang Z, Li T-B, Lou Z, Li S-Y, Yang H, Yang J, Luo X-J, Peng J (2014) Up-regulation of brain-enriched miR-107 promotes excitatory neurotoxicity through down-regulation of glutamate transporter-1 expression following ischaemic stroke. Clin. Sci. (Lond).127, 679-89.

[30] He J, Zhang W, Zhou Q, Zhao T, Song Y, Chai L, Li Y (2013) Low-expression of microRNA-107 inhibits cell apoptosis in glioma by upregulation of SALL4. Int. J. Biochem. Cell Biol.45, 1962-1973.

[31] Zhu M, Huang C, Ma X, Wu R, Zhu W, Li X, Liang Z, Deng F, Zhu J, Xie W, Yang X, Jiang Y, Wang S, Wu J, Geng S, Xie C, Zhong C (2016) Modulation of miR-19 in Aluminum-Induced Neural Cell Apoptosis. J. Alzheimer's Dis.50, 1149-1162.

[32] Baumgartner U, Berger F, Hashemi Gheinani A, Burgener SS, Monastyrskaya K, Vassella E (2018) miR-19b enhances proliferation and apoptosis resistance via the EGFR signaling pathway by targeting PP2A and BIM in non-small cell lung cancer. Mol. Cancer17, 44.

[33] Ham O, Lee S-Y, Lee CY, Park J-H, Lee J, Seo H-H, Cha M-J, Choi E, Kim S, Hwang K-C (2015) let-7b suppresses apoptosis and autophagy of human mesenchymal stem cells transplanted into ischemia/reperfusion injured heart 7 by targeting caspase-3. Stem Cell Res. Ther.6, 147.

[34] Lehmann SM, Krüger C, Park B, Derkow K, Rosenberger K, Baumgart J, Trimbuch T, Eom G, Hinz M, Kaul D, Habbel P, Kälin R, Franzoni E, Rybak A, Nguyen D, Veh R, Ninnemann O, Peters O, Nitsch R, Heppner FL, Golenbock D, Schott E, Ploegh HL, Wulczyn FG, Lehnardt S (2012) An unconventional role for miRNA: let-7 activates Toll-like receptor 7 and causes neurodegeneration. Nat. Neurosci.15, 827-35.

[35] Absalon S, Kochanek DM, Raghavan V, Krichevsky AM (2013) MiR-26b, Upregulated in Alzheimer's Disease, Activates Cell Cycle Entry, Tau-Phosphorylation, and Apoptosis in Postmitotic Neurons. J. Neurosci.33, 14645-14659.

[36] Li Y-P, Dai W-M, Huang Q, Jie Y-Q, Yu G-F, Fan X-F, Wu A, Mao D-D (2017) Effects of microRNA-26b on proliferation and invasion of glioma cells and related mechanisms. Mol. Med. Rep.16, 4165-4170.

[37] Jin F, Wang Y, Li M, Zhu Y, Liang H, Wang C, Wang F, Zhang C-Y, Zen K, Li L (2017) MiR-26 enhances chemosensitivity and promotes apoptosis of hepatocellular carcinoma cells through inhibiting autophagy. Cell Death Dis.8, e2540.

[38] He Q-Q, Xiong L-L, Liu F, He X, Feng G-Y, Shang F-F, Xia Q-J, Wang Y-C, Qiu DL, Luo C-Z, Liu J, Wang T-H (2016) MicroRNA-127 targeting of mitoNEET inhibits neurite outgrowth, induces cell apoptosis and contributes to physiological dysfunction after spinal cord transection. Sci. Rep.6, 35205.

[39] Feng R, Dong L (2015) Knockdown of microRNA-127 reverses adriamycin resistance via cell cycle arrest and apoptosis sensitization in adriamycin-resistant human glioma cells. Int. J. Clin. Exp. Pathol.8, 6107-16.

[40] Wang S, Li H, Wang J, Wang D, Yao A, Li Q (2014) Prognostic and Biological Significance of MicroRNA-127 Expression in Human Breast Cancer. Dis. Markers 2014, 1-12.

[41] Chen X, Qu Y, Cheng Y, Wang J, Lei X, Song G, Zhang H, Wang H, Lei F (2018) MiR-19b-3p Regulates MAPK1 Expression in Embryonic Fibroblasts from the Great Tit (Parus Major) Under Hypoxic Conditions. Cell. Physiol. Biochem.46, 546-560.

[42] Neary D, Snowden JS, Gustafson L, Passant U, Stuss D, Black S, Freedman M, Kertesz A, Robert PH, Albert M, Boone K, Miller BL, Cummings J, Benson DF (1998) Frontotemporal lobar degeneration: a consensus on clinical diagnostic criteria. Neurology51, 1546-54. 
[43] Rascovsky K, Hodges JR, Knopman D, Mendez MF, Kramer JH, Neuhaus J, van Swieten JC, Seelaar H, Dopper EGP, Onyike CU, Hillis AE, Josephs KA, Boeve BF, Kertesz A, Seeley WW, Rankin KP, Johnson JK, Gorno-Tempini M-L, Rosen H, Prioleau-Latham CE, Lee A, Kipps CM, Lillo P, Piguet O, Rohrer JD, Rossor MN, Warren JD, Fox NC, Galasko D, Salmon DP, Black SE, Mesulam M, Weintraub S, Dickerson BC, Diehl-Schmid J, Pasquier F, Deramecourt V, Lebert F, Pijnenburg Y, Chow TW, Manes F, Grafman J, Cappa SF, Freedman M, Grossman M, Miller BL (2011) Sensitivity of revised diagnostic criteria for the behavioural variant of frontotemporal dementia. Brain 134, 2456-77.

[44] McKhann G, Drachman D, Folstein M, Katzman R, Price D, Stadlan EM (1984) Clinical diagnosis of Alzheimer's disease: report of the NINCDS-ADRDA Work Group under the auspices of Department of Health and Human Services Task Force on Alzheimer's Disease. Neurology34, 939-44.

[45] Blondal T, Nielsen SJ, Baker A, Andreasen D, Mouritzen P, Teilum MW, Dahlsveen IK (2013) Assessing sample and miRNA profile quality in serum and plasma or other biofluids. Methods59, 164-169.

[46] Vandesompele J, De Preter K, Pattyn F, Poppe B, Van Roy N, De Paepe A, Speleman F (2002) Accurate normalization of real-time quantitative RT-PCR data by geometric averaging of multiple internal control genes. Genome Biol.3, RESEARCH0034.

[47] Andersen CL, Jensen JL, Ørntoft TF (2004) Normalization of real-time quantitative reverse transcription-PCR data: a model-based variance estimation approach to identify genes suited for normalization, applied to bladder and colon cancer data sets. Cancer Res.64, 5245-50.

[48] Zhang C, Wang C, Chen X, Yang C, Li K, Wang J, Dai J, Hu Z, Zhou X, Chen L, Zhang Y, Li Y, Qiu H, Xing J, Liang Z, Ren B, Yang C, Zen K, Zhang C-Y (2010) Expression Profile of MicroRNAs in Serum: A Fingerprint for Esophageal Squamous Cell Carcinoma. Clin. Chem.56, 1871-1879.

[49] Mian C, Pennelli G, Fassan M, Balistreri M, Barollo S, Cavedon E, Galuppini F, Pizzi M, Vianello F, Pelizzo MR, Girelli ME, Rugge M, Opocher G (2012) MicroRNA Profiles in Familial and Sporadic Medullary Thyroid Carcinoma: Preliminary Relationships with RET Status and Outcome. Thyroid22, 890-896.

[50] Khudayberdiev SA, Zampa F, Rajman M, Schratt G (2013) A comprehensive characterization of the nuclear microRNA repertoire of post-mitotic neurons. Front. Mol. Neurosci.6, 43.

[51] Miska EA, Alvarez-Saavedra E, Townsend M, Yoshii A, Šestan N, Rakic P, Constantine-Paton M, Horvitz HR (2004) Microarray analysis of microRNA expression in the developing mammalian brain. Genome Biol.5, R68.

[52] Pan C, Chen H, Wang L, Yang S, Fu H, Zheng Y, Miao M, Jiao B (2012) DownRegulation of MiR-127 Facilitates Hepatocyte Proliferation during Rat Liver Regeneration. PLoS One7, e39151.

[53] Chen J, Wang M, Guo M, Xie Y, Cong Y-S (2013) miR-127 Regulates Cell Proliferation and Senescence by Targeting BCL6. PLoS One8, e80266.

[54] Burgos K, Malenica I, Metpally R, Courtright A, Rakela B, Beach T, Shill H, Adler C, Sabbagh M, Villa S, Tembe W, Craig D, Van Keuren-Jensen K (2014) Profiles of Extracellular miRNA in Cerebrospinal Fluid and Serum from Patients with Alzheimer's and Parkinson's Diseases Correlate with Disease Status and Features of Pathology. PLoS One9, e94839.

[55] Ebrahimkhani S, Vafaee F, Young PE, Hur SSJ, Hawke S, Devenney E, Beadnall H, Barnett MH, Suter CM, Buckland ME (2017) Exosomal microRNA signatures in multiple sclerosis reflect disease status. Sci. Rep.7, 14293. 
[56] Sørensen SS, Nygaard A-B, Christensen T (2016) miRNA expression profiles in cerebrospinal fluid and blood of patients with Alzheimer's disease and other types of dementia - an exploratory study. Transl. Neurodegener.5, 6.

[57] Sheinerman KS, Toledo JB, Tsivinsky VG, Irwin D, Grossman M, Weintraub D, Hurtig HI, Chen-Plotkin A, Wolk DA, McCluskey LF, Elman LB, Trojanowski JQ, Umansky SR (2017) Circulating brain-enriched microRNAs as novel biomarkers for detection and differentiation of neurodegenerative diseases. Alzheimers. Res. Ther.9, 89.

[58] Vallelunga A, Ragusa M, Di Mauro S, Iannitti T, Pilleri M, Biundo R, Weis L, Di Pietro C, De Iuliis A, Nicoletti A, Zappia M, Purrello M, Antonini A (2014) Identification of circulating microRNAs for the differential diagnosis of Parkinson's disease and Multiple System Atrophy. Front. Cell. Neurosci.8, 156.

[59] Song G, Wang L (2009) A Conserved Gene Structure and Expression Regulation of miR-433 and miR-127 in Mammals. PLoS One4, e7829.

[60] Sharma S, Eghbali M (2014) Influence of sex differences on microRNA gene regulation in disease. Biol. Sex Differ.5, 3.

[61] Ziats MN, Rennert OM (2014) Identification of differentially expressed microRNAs across the developing human brain. Mol. Psychiatry 19, 848-852.

[62] Denk J, Boelmans K, Siegismund C, Lassner D, Arlt S, Jahn H (2015) MicroRNA Profiling of CSF Reveals Potential Biomarkers to Detect Alzheimer`s Disease. PLoS One10, e0126423.

[63] Mellios N, Galdzicka M, Ginns E, Baker SP, Rogaev E, Xu J, Akbarian S (2012) Gender-specific reduction of estrogen-sensitive small RNA, miR-30b, in subjects with schizophrenia. Schizophr. Bull.38, 433-43.

[64] Pietraforte D, Straface E, Piscopo P, Vona R, Confaloni A (2016) Sex-related biomarkers in cardiovascular and neurodegenerative disorders. Ann Ist Super Sanità52, 230-239.

[65] Sachdev PS, Lipnicki DM, Kochan NA, Crawford JD, Thalamuthu A, Andrews G, Brayne C, Matthews FE, Stephan BCM, Lipton RB, Katz MJ, Ritchie K, Carrière I, Ancelin M-L, Lam LCW, Wong CHY, Fung AWT, Guaita A, Vaccaro R, Davin A, Ganguli M, Dodge H, Hughes T, Anstey KJ, Cherbuin N, Butterworth P, Ng TP, Gao Q, Reppermund S, Brodaty H, Schupf N, Manly J, Stern Y, Lobo A, Lopez-Anton R, Santabárbara J, Cohort Studies of Memory in an International Consortium (COSMIC) M, Derby C, Leung GTY, Chan WC, Polito L, Abbondanza S, Valle E, Colombo M, Vitali SF, Fossi S, Zaccaria D, Forloni G, Villani S, Christensen H, MacKinnon A, Easteal S, Jacomb T, Maxwell K, Bowman A, Burns K, Broe A, Dekker J, Dooley L, Permentier M De, Fairjones S, Fletcher J, French T, Foster C, Nugent-Cleary-Fox E, Gooi C, Harvey E, Helyer R, Hsieh S, Hughes L, Jacek S, Johnston M, McCade D, Meeth S, Milne E, Moir A, O'Grady R, Pfaeffli K, Pose C, Reuser L, Rose A, Schofield P, Shahnawaz Z, Sharpley A, Thompson C, Queisser W, Wong S, Mayeux R, Brickman A, Luchsinger J, Sanchez D, Tang MX, Andrews H, Marcos G, De-LaCámara C, Saz P, Ventura T, Quintanilla MA, Lobo E (2015) The Prevalence of Mild Cognitive Impairment in Diverse Geographical and Ethnocultural Regions: The COSMIC Collaboration. PLoS One10, e 0142388.

[66] Mitchell AJ, Shiri-Feshki M (2009) Rate of progression of mild cognitive impairment to dementia - meta-analysis of 41 robust inception cohort studies. Acta Psychiatr. Scand.119, 252-265.

[67] Canevelli M, Grande G, Lacorte E, Quarchioni E, Cesari M, Mariani C, Bruno G, Vanacore N (2016) Spontaneous Reversion of Mild Cognitive Impairment to Normal Cognition: A Systematic Review of Literature and Meta-Analysis. J. Am. Med. Dir. 
Assoc. 17, 943-948.

[68] Piscopo P, Tosto G, Belli C, Talarico G, Galimberti D, Gasparini M, Canevelli M, Poleggi A, Crestini A, Albani D, Forloni G, Lucca U, Quadri P, Tettamanti M, Fenoglio C, Scarpini E, Bruno G, Vanacore N, Confaloni A (2015) SORL1 Gene is Associated with the Conversion from Mild Cognitive Impairment to Alzheimer's Disease. J. Alzheimer's Dis.46, 771-776. 


\section{Figure legends}

Figure 1. Box plots show the distribution of miR-127-3p values in AD (n=20), Ctrl $(n=53)$ and FTD $(n=54)$ subjects.

The line in the middle of the box represents the median. The box extends from the 25 th percentile $(x[25])$ to the 75 th percentile $(x[75])$, the so-called interquartile range (IQ). The lines emerging from the box extend to the upper and lower adjacent values. The upper adjacent value is defined as the largest data point less than or equal to $x[75]+1.5 \mathrm{IQ}$. The lower adjacent value is the smallest data point greater than or equal to $x$ [25] - 1.5 IQ. Dots indicate observed data points more extreme than the adjacent values (referred to as outliers).

Figure 2. Scatter plots of miR-127-3p expression levels in FTD vs Ctrl and in FTD vs AD in males and females.

Figure 3. ROC curves of miR-127-3p.

Receiver operating characteristic curve of differentially expressed miR-127-3p in A) FTD vs Ctrl and B) FTD vs AD. 
Table 1. Demographic and clinical features of subjects in the study

\begin{tabular}{|c|c|c|c|c|c|c|}
\hline & $\begin{array}{c}\text { Ctrl } \\
(n=53)\end{array}$ & $\operatorname{AD}(n=20)$ & $\begin{array}{c}\text { FTD } \\
(n=54)\end{array}$ & $\begin{array}{l}\text { AD vs } \\
\text { Ctrl }\end{array}$ & $\begin{array}{l}\text { FTD vs } \\
\text { Ctrl }\end{array}$ & FTD vs AD \\
\hline F $(\%)$ & $33(62)$ & $10(50)$ & $35(65)$ & \multirow{2}{*}{\multicolumn{3}{|c|}{$0.504^{1}($ Overall $)$}} \\
\hline M (\%) & $20(38)$ & $10(50)$ & $19(35)$ & & & \\
\hline $\begin{array}{c}\text { Age at evaluation } \\
\text { Mean (SE) }\end{array}$ & $71.6(1.0)$ & $71.3(1.8)$ & $70.3(1.2)$ & $0.8844^{2}$ & $0.3877^{2}$ & $0.6307^{2}$ \\
\hline $\begin{array}{c}\text { MMSE } \\
\text { Median (IQR) }\end{array}$ & & $18.5(10.5)$ & $22(13)$ & & & ns $(0.0920)$ \\
\hline $\begin{array}{c}\text { Disease duration } \\
\text { at evaluation } \\
\text { Median (IQR) }\end{array}$ & & $4.5(4)$ & $4(4)$ & & & ns \\
\hline
\end{tabular}

1: Fisher's exact probability test

2: t-test

Table 2. Comparisons among groups (Ctrl, AD and FTD) of miR-127-3p levels

The table shows the number of subjects in each group, the average raw $\mathbf{2}^{-\mathbf{A C t}}$ and standard error of miR-127-3p levels, and $p$ value for each comparison.

\begin{tabular}{|c|c|c|c|c|c|}
\hline \multicolumn{3}{|c|}{$\begin{array}{c}\mathbf{2}^{-\boldsymbol{\Delta C t}} \\
\text { Mean (SE) }\end{array}$} & \multicolumn{3}{|c|}{ p value } \\
\hline $\operatorname{Ctrl}(n=53)$ & $\operatorname{AD}(n=20)$ & FTD $(n=54)$ & AD vs Ctrl & FTD vs Ctrl & FTD vs AD \\
\hline $\begin{array}{c}0.058 \\
(0.007)\end{array}$ & $0.078(0.014)$ & $0.017(0.003)$ & 0.1796 & $<0.0001$ & $<0.0001$ \\
\hline
\end{tabular}


Table 3.Accuracy of $\Delta \mathrm{CT}$ criteria by study population

\begin{tabular}{|c|c|c|c|c|c|c|c|c|c|c|c|c|}
\hline \multirow[b]{2}{*}{ Cutpoint } & \multirow[b]{2}{*}{$\Delta \mathbf{C t}$} & \multirow[b]{2}{*}{$\begin{array}{l}2^{-} \\
\Delta \mathrm{Ct}\end{array}$} & \multicolumn{5}{|l|}{ AD vs FTD } & \multicolumn{5}{|l|}{ Ctrl vs FTD } \\
\hline & & & Sensitivity & Specificity & Correctly Classified & $\mathbf{L R}+$ & LR- & Sensitivity & Specificity & Correctly Classified & $\mathbf{L R}+$ & LR- \\
\hline$(>=3.395)$ & 3.40 & 0.10 & $100.00 \%$ & $35.00 \%$ & $82.43 \%$ & 1.5385 & 0 & $100.00 \%$ & $20.75 \%$ & $60.75 \%$ & 1.2619 & 0 \\
\hline$(>=4.255)$ & 4.26 & 0.05 & $90.74 \%$ & $55.00 \%$ & $81.08 \%$ & 2.0165 & 0.1684 & $90.74 \%$ & $35.85 \%$ & $63.55 \%$ & 1.4145 & 0.2583 \\
\hline$(>=5.495)$ & 5.50 & 0.02 & $81.48 \%$ & $80.00 \%$ & $81.08 \%$ & 4.0741 & 0.2315 & $81.48 \%$ & $69.81 \%$ & $75.70 \%$ & 2.6991 & 0.2653 \\
\hline$(>=5.94)$ & 5.94 & 0.02 & $70.37 \%$ & $90.00 \%$ & $75.68 \%$ & 7.037 & 0.3292 & $70.37 \%$ & $77.36 \%$ & $73.83 \%$ & 3.108 & 0.383 \\
\hline
\end{tabular}

\section{Figure 1}

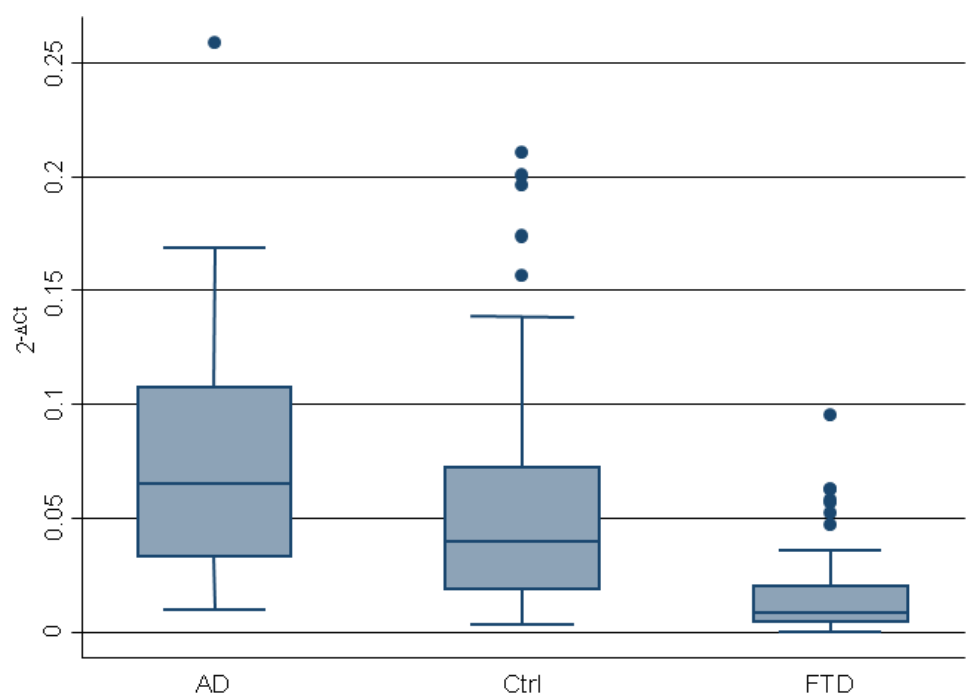


Figure 2

A

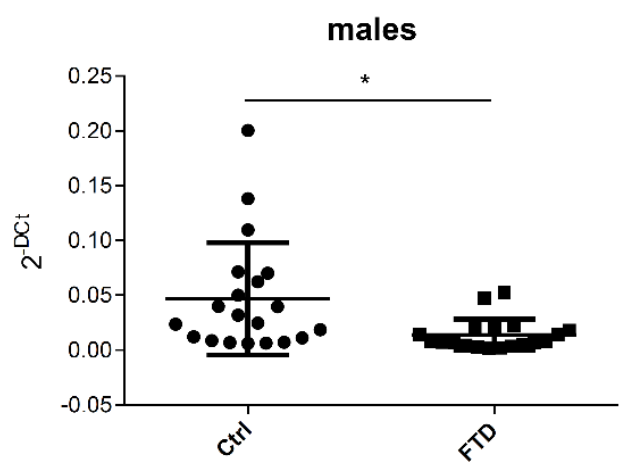

C

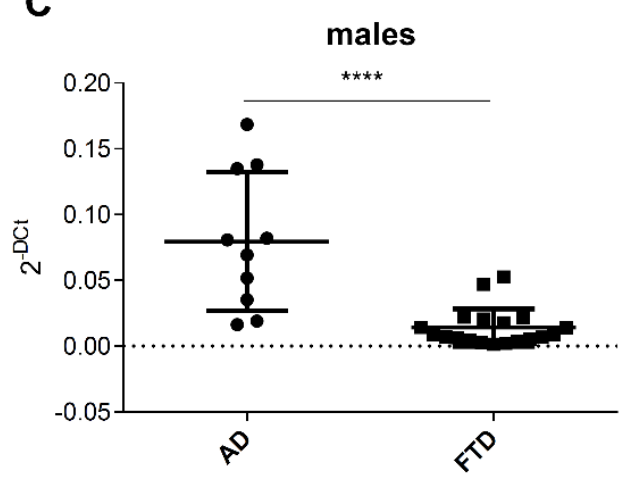

B

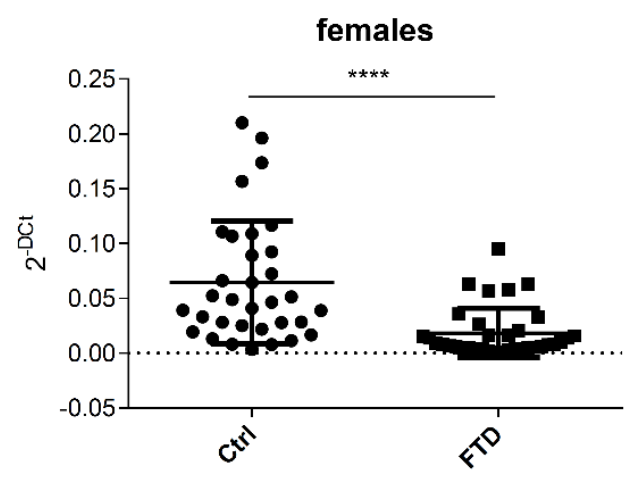

D

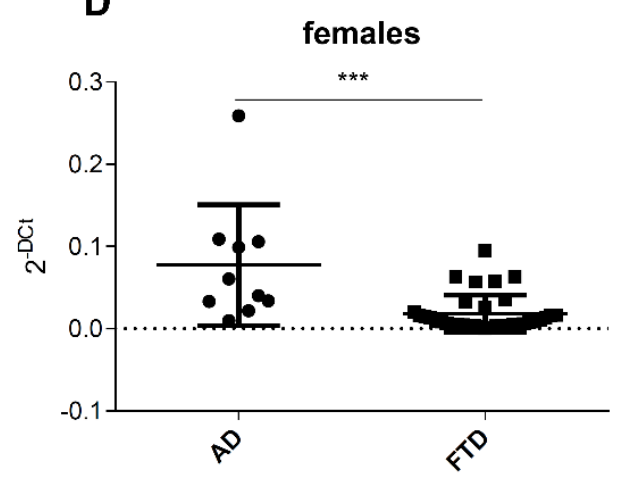


Figure 3

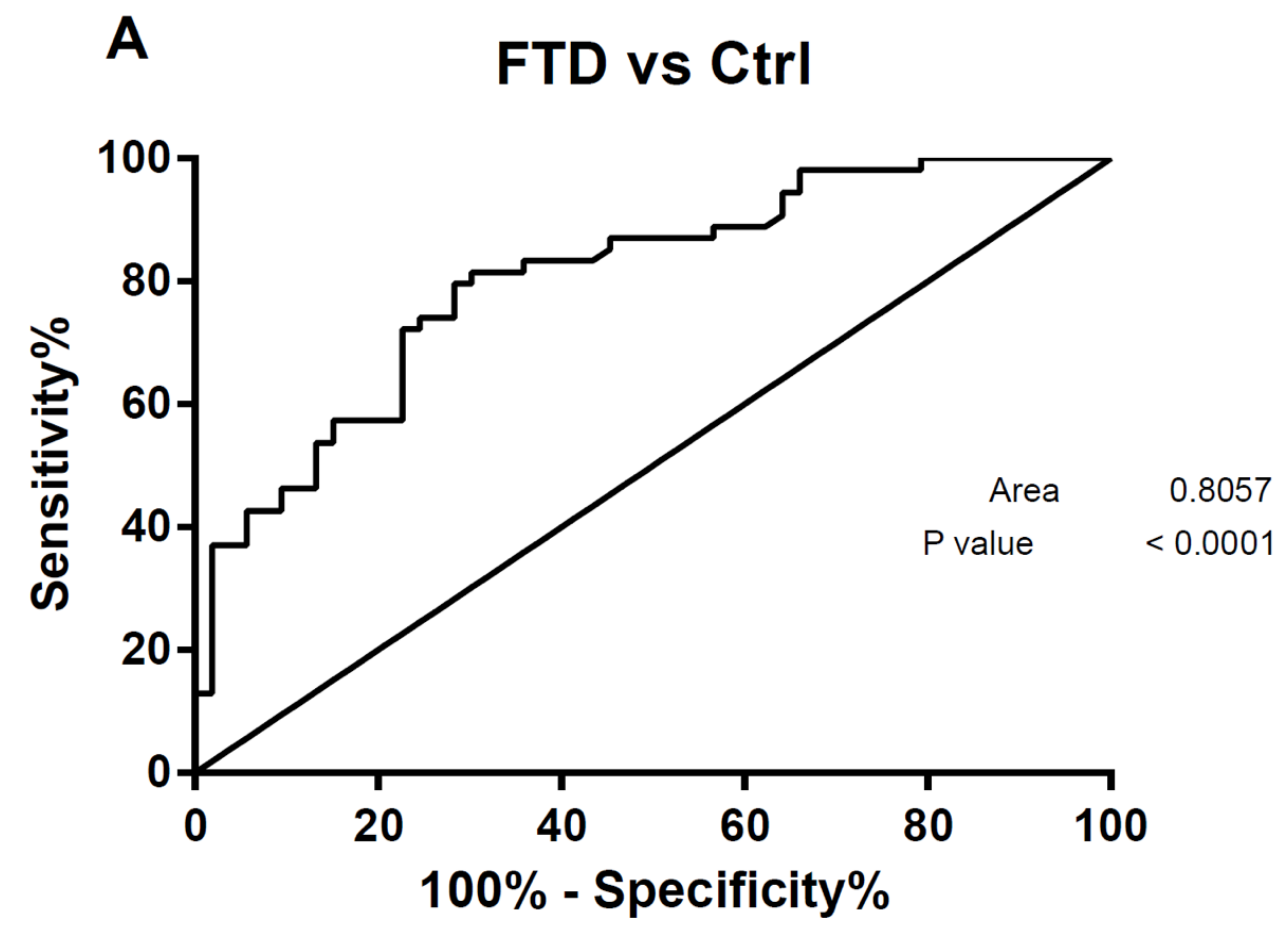

B

FTD vs AD

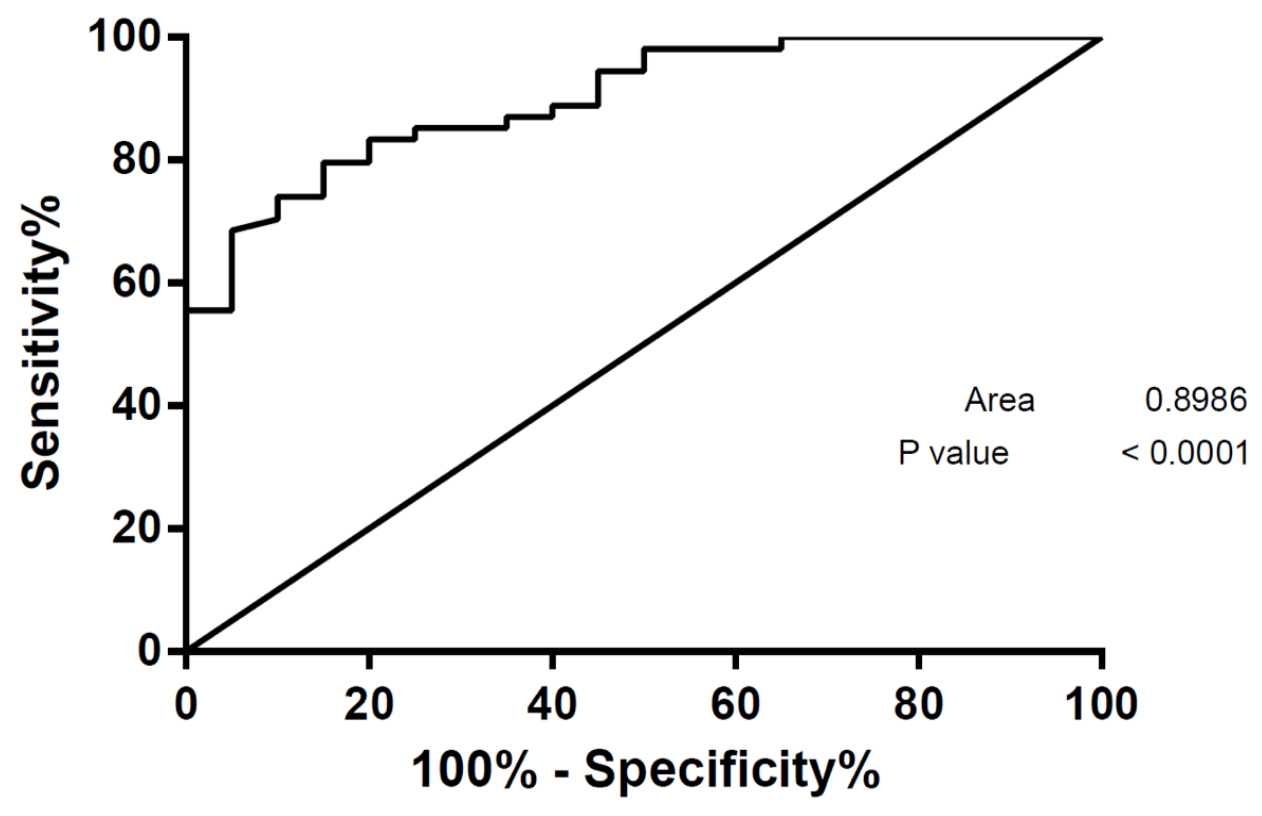


Figure 4
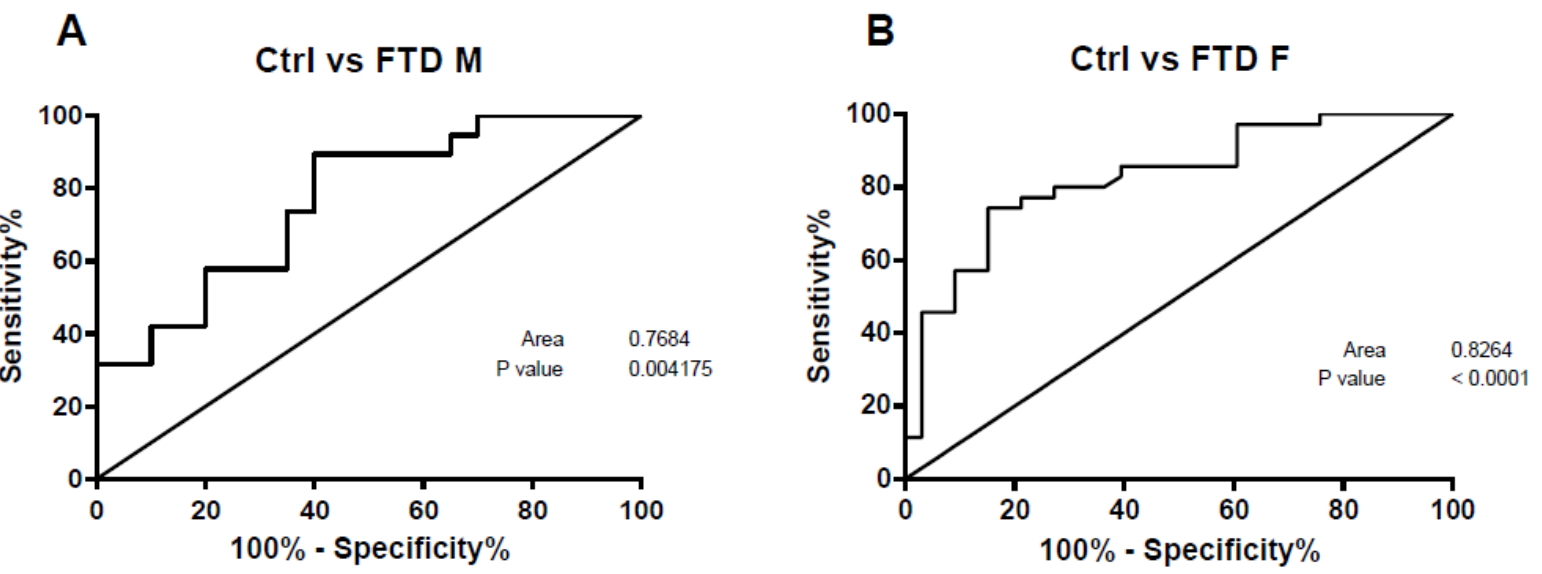

C

\section{FTD vs AD M}

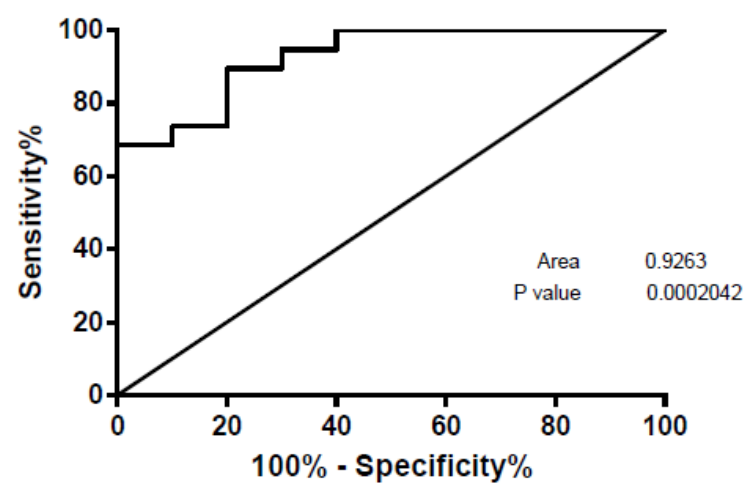

\section{FTD vs $A D F$}

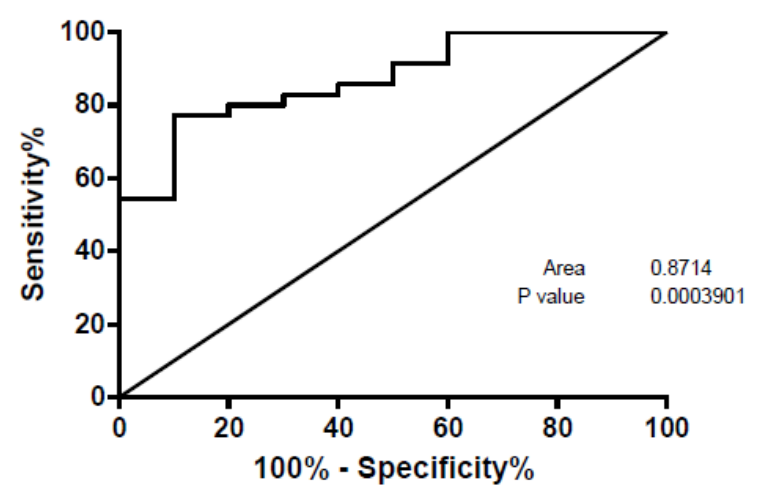




\section{Supplementary Material}

Supplementary Figure 1. Scatter plots of reference genes selected to normalize analyzed miRNAs.

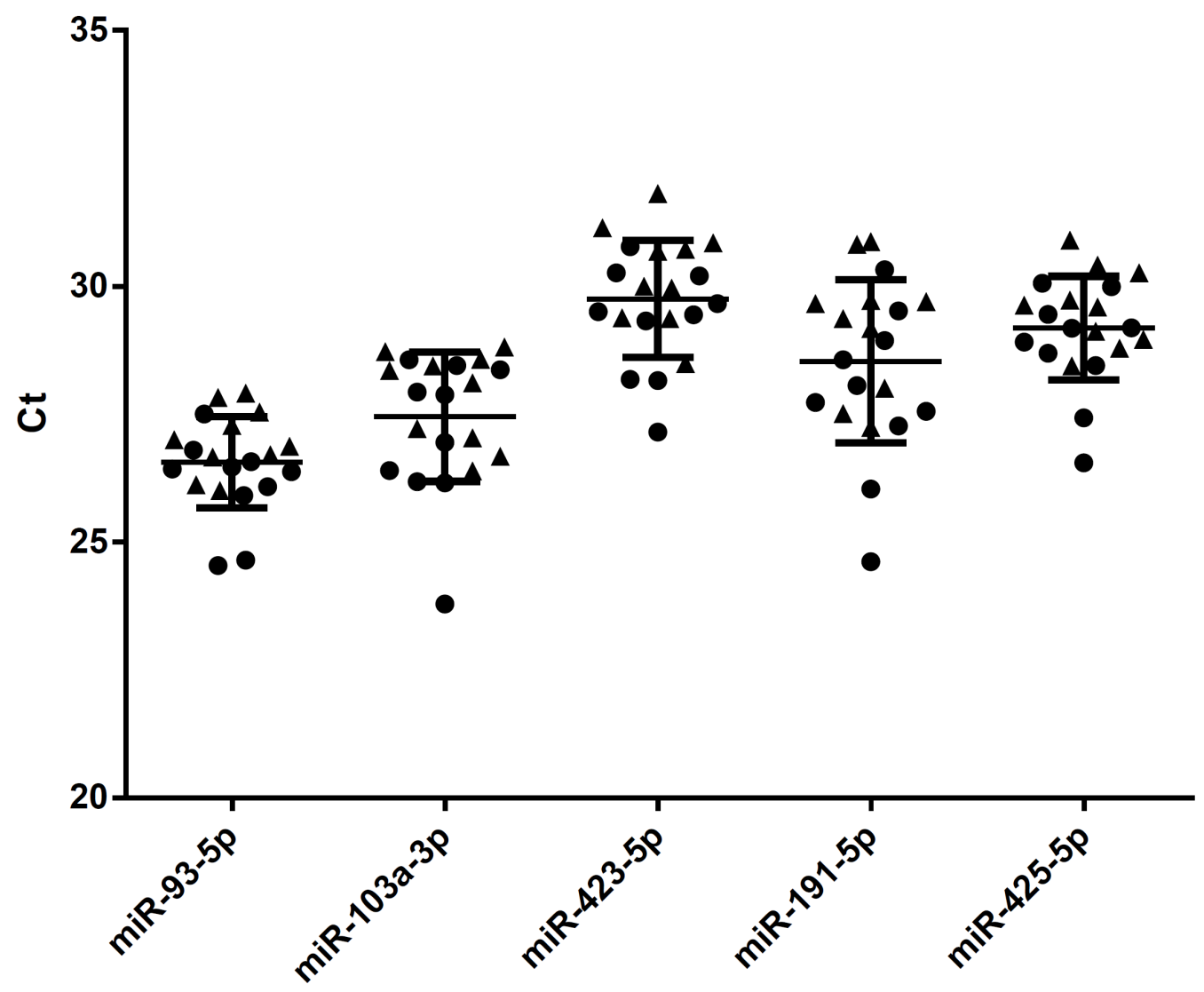


Supplementary Figure 2. Scatter plots of miR-29b-3p, miR-34a-5p, miR-16-5p, miR-17-5p, miR-107, miR19b-3p, let-7b-5p and miR-26b-5p in Ctrl vs FTD patients.

miR-29b-3p

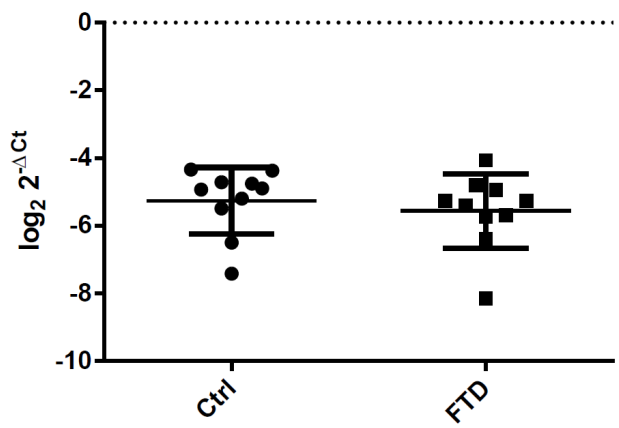

$\operatorname{miR}-16-5 p$

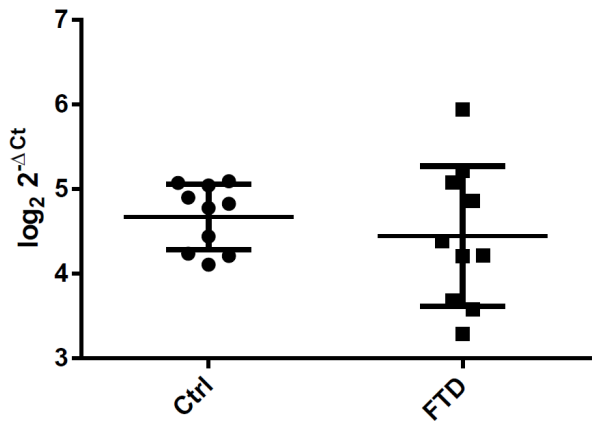

miR-107

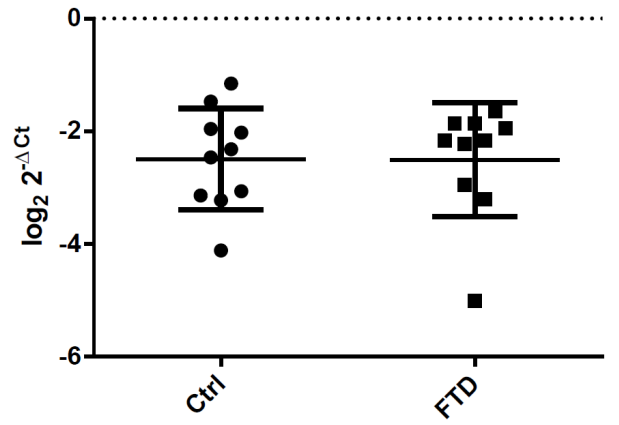

let-7b-5p

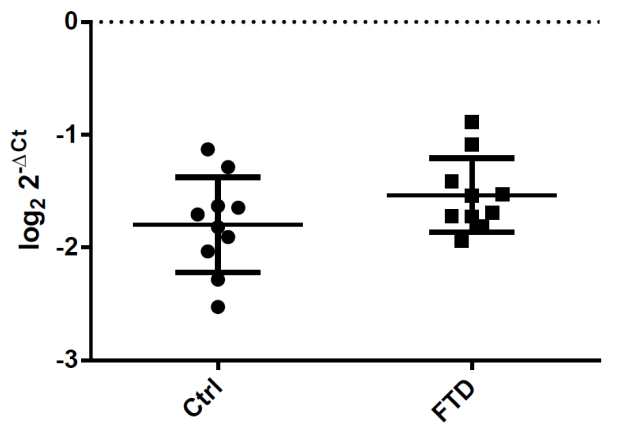

miR-34a-5p

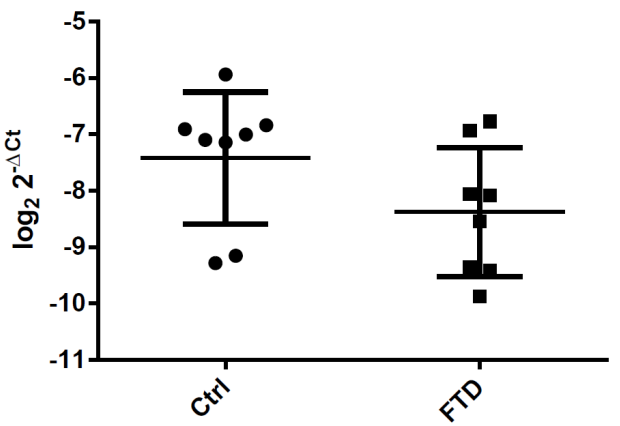

miR-17-5p

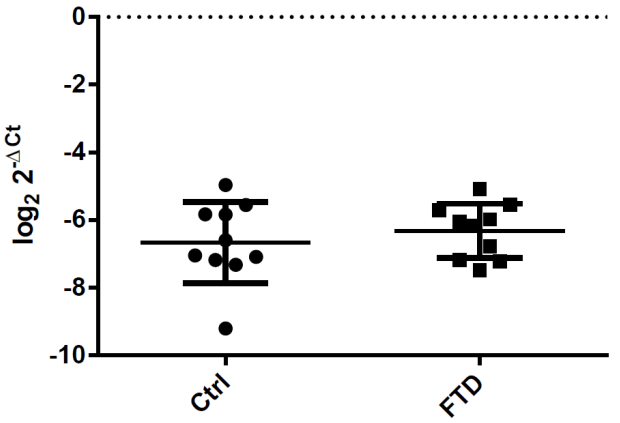

miR-19b-3p

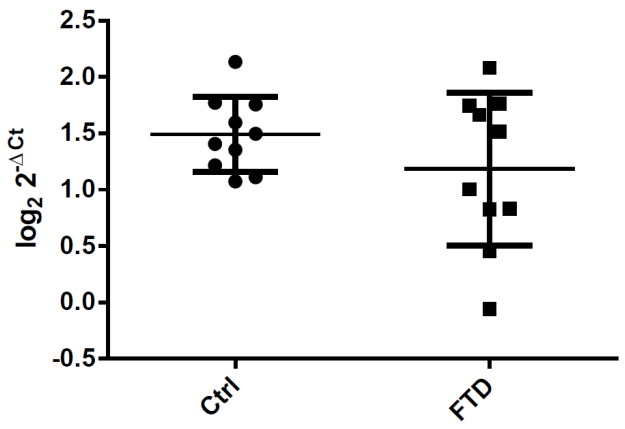

miR-26b-5p

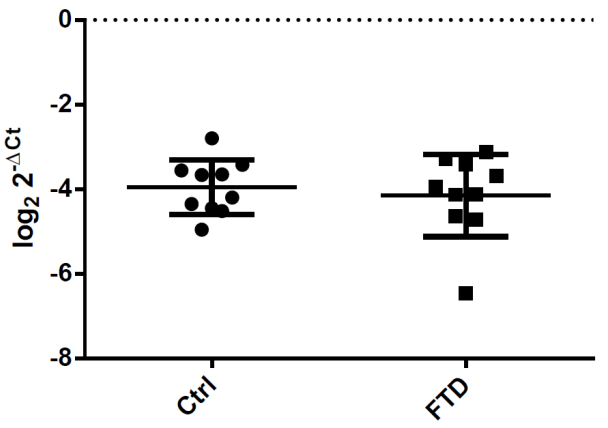


Supplementary Figure 3

ROC curves of miR-127-3p for FTD vs Ctrl (A) and FTD vs AD (B) excluding outliers identified in box plots.

A

FTD vs Ctrl no outliers

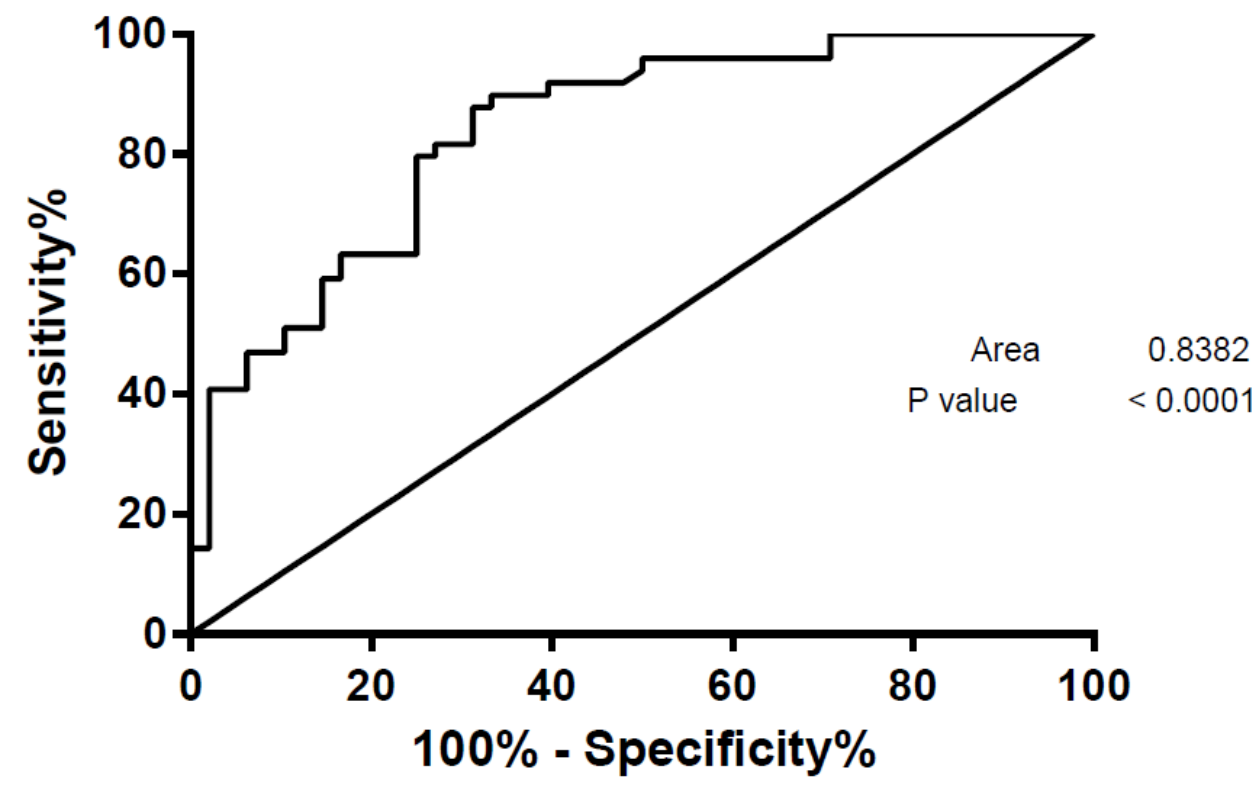

B

FTD vs AD no outliers

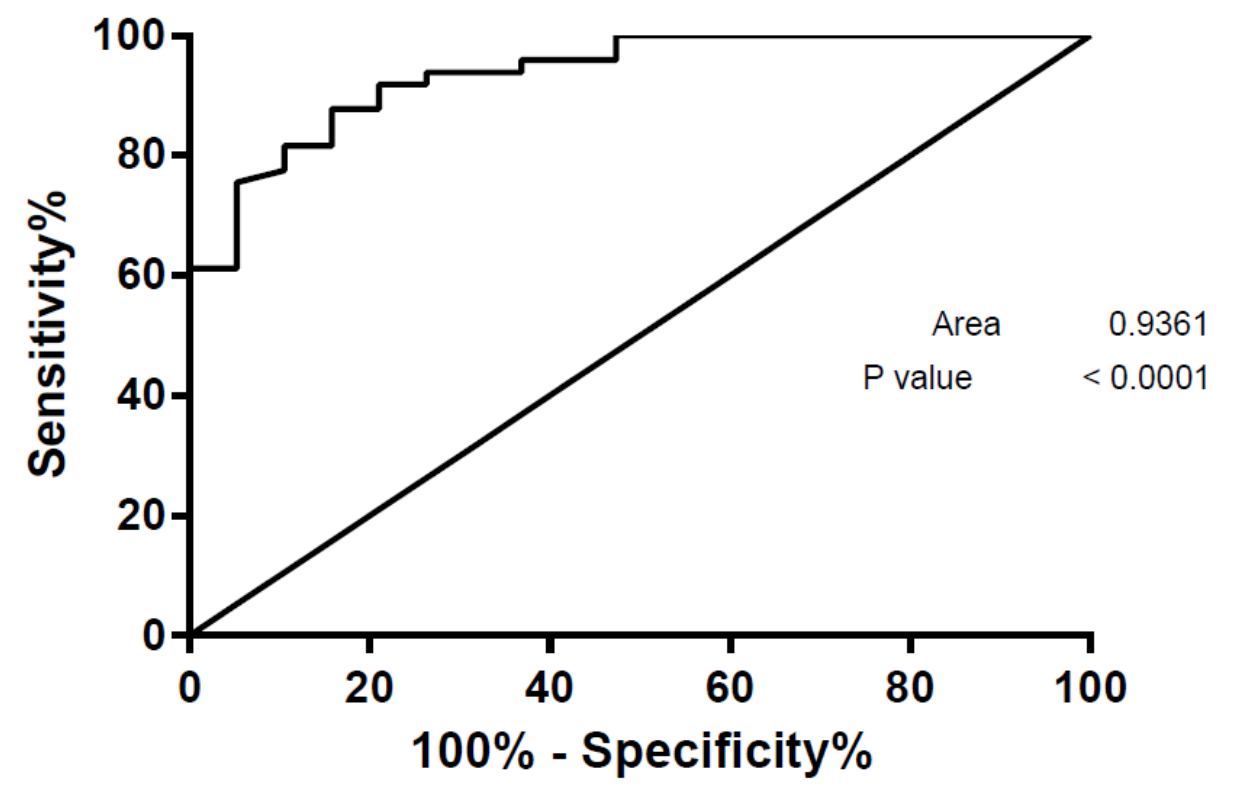

